\title{
ANALISIS JARINGAN SOSIAL PADA ARTIKEL TERKAIT USAHA KECIL DAN MENENGAH DI INDONESIA
}

\author{
Aris Yaman \\ Pusat Inovasi - Lembaga Ilmu Pengetahuan Indonesia \\ Korespondensi: aris.yaman@gmail.com
}

Diajukan: 26 Oktober 2016; Direview: 23 Maret 2017; Diterima: 24 Maret 2017; Direvisi: 26 Maret 2017

\begin{abstract}
The amount of contribution of SMEs to be balanced by a reception with great competitiveness. Innovation is a way of improving competitiveness. Contributions researchers and academics can be seen from innovations made through scientific publications. The government should provide incentives to researchers who focus on the development of Indonesian SMEs to improve the nation's competitiveness. Due to budget constraints, the government needs to streamline and streamline the budget incentives for research related to SMEs Indonesia. In addition to seeing the productivity aspects of scientific publications, is necessary to study the centrality of a writer/agency relationships in social network analysis co-authorship. In terms of productivity Institut Teknologi Bandung (ITB) become the most productive agencies to publish articles related to SMEs Indonesia. Judging from the social networking aspect, the University of Indonesia became the central figure in scientific publications related to SMEs Indonesia. Thus, social network analysis co-authorship relations can be used as another aspect in determining the actor/isntansi influential scientific publications related to SMEs in Indonesia.
\end{abstract}

\begin{abstract}
ABSTRAK
Besarnya kontribusi UKM terhadap penerimaan negara perlu diimbangi dengan daya saing yang besar. Inovasi merupakan salah satu jalan untuk meningkatkan daya saing. Kontribusi peneliti dan akademisi dapat dilihat dari inovasi yang dilakukan melalui publikasi ilmiah. Pemerintah perlu memberikan insentif kepada peneliti yang fokus pada pengembangan UKM Indonesia untuk meningkatkan daya saing bangsa. Karena keterbatasan anggaran belanja, pemerintah perlu mengefektifkan dan mengefisienkan anggaran untuk penelitian tentang UKM Indonesia. Selain melihat aspek produktivitas publikasi ilmiah, perlu dikaji sentralitas seorang penulis/instansi dalam analisis jaringan sosial hubungan co-authorship. Dari sisi produktivitas ITB menjadi instansi yang paling produktif mempublikasikan artikel tentang UKM Indonesia. Dilihat dari aspek jaringan sosial, UI menjadi tokoh sentral dalam publikasi ilmiah tentang UKM Indonesia. Sehingga, analisis jaringan sosial hubungan co-authorship dapat dijadikan aspek lain dalam menentukan aktor/instansi yang berpengaruh dalam publikasi ilmiah tentang UKM Indonesia.
\end{abstract}

Keywords: Co-authorship; Social network analysis; SME's competitiveness; Scientometric; UKM Indonesia

\section{PENDAHULUAN}

Hampir sebagian perkembangan ekonomi di berbagai negara dipengaruhi oleh kinerja UKM (Aharoni, 1994). Hal yang sama terjadi di Indonesia, pada tahun 2012 UMKM mempunyai andil besar terhadap penerimaan negara dengan menyumbang 59,08\% pemasukan produk domestic bruto PDB melalui pembayaran pajak (Koperasi dan UKM, 2015). Akan tetapi, besarnya kontribusi ini tidak diimbangi dengan daya saing yang tinggi, laporan World Economic Forum (WEF) menyebutkan bahwa daya saing Indonesia periode 2015 - 2016 turun tiga level ke peringkat 41 . WEF juga menyebutkan salah satu dari 12 pilar yang dapat 
meningkat daya saing adalah pilar inovasi (Schwab, Sala-i-Martin, \& Brende, 2015). Oleh karena itu, pemerintah harus meningkatkan peran akademsi dan peneliti untuk meningkatkan daya saing bangsa, khusunya daya saing UKM.

Di tengah kondisi perekonomian Indonesia yang melemah, pada tahun 2015 dan 2016 pemerintah terpaksa memotong anggaran penelitian. Hal ini berdampak kontradiktif terhadap peningkatan pilar inovasi bangsa. Untuk mengefektifkan pendanaan riset yang terbatas tentunya diperlukan strategi kebijakan pendanaan riset yang tepat. Salah satu satu cara yang dapat dilakukan, yaitu selektif memberikan pendanaan secara insentif penelitian kepada peneliti atau instansi yang memang berkontribusi besar dalam penelitian dalam bidang tertentu. Salah satu cabang ilmu yang dapat mengukur dan menganalisis terhadap kebijakan Iptek, yaitu dengan Scientometric. Terkait pengambilan kebijakan anggaran penelitian dan pengembangan (litbang) dalam keilmuan scientometrics ini perlu analisis terhadap jaringan penulis (coauthorship network) untuk bahan pengambilan kebijakan. Analisis co-authorship networks ini memberikan informasi terkait penulis paling produktif; penulis yang banyak bekerjasama dengan penulis lain; performa institusi dalam jaringan hingga bagaimana hubungan antar institusi. Melalui informasi ini diperoleh bahan pertimbangan dalam penyaluran anggaran yang dapat memberikan dampak yang lebih tinggi bagi masyarakat (Nadhiroh, Aidi, \& Sartono, 2015).

\section{TINJAUAN PUSTAKA}

\subsection{Co-Authorship Networks}

Co-authorship terjadi ketika dua orang penulis menulis bersama dalam tulisan yang sama. Co-auhtorship adalah bentuk paling nyata dan baik sebuah kolaborasi dokumentasi ilmiah (Glänzel \& Schubert, 2005). Co-authorship lebih berimplikasi sosial jika dibandingkan dengan sitasi. Hal ini dikarenakan sitasi dapat dilakukan tanpa berkomunikasi atau berhubungan langsung dengan penulis yang disitasinya, berbeda dengan co-authorship yang dapat dipastikan antar-penulis terjalin komunikasi dan hubungan sosial secara langsung antar-penulis dalam tulisan yang sama. Co-authorship menyiratkan hubungan temporal dan kolegial yang menempatkan lebih tepat dalam ranah analisis jaringan sosial (Liu, Bollen, Nelson, \& Van De Sompel, 2005). Co-authorship networks menggambarkan jaringan tim peneliti, faktor yang mempengaruhi co-authorship, dampak dan output dari kolaborasi, dan struktur sosial dari area tulisan. Untuk menggambarkan hal tersebut perlu dilakukan analisis jaringan sosial atau Social Network Anaysis/SNA) (Zupic \& Čater, 2014).

\subsection{Social Networks Analysis}

Analisis jaringan sosial/SNA merupakan suatu paradigma untuk menjelaskan bentuk struktur dalam hubungan sosial, metode untuk menjelaskan dan menguji proses sharing informasi, dan mengidentifikasi kemacetan arus informasi (Salamati \& Soheili, 2016). Peranan individu dalam analisis jaringan sosial menjadi penting karena dapat mengidentifikasi individu-individu yang dianggap paling penting dalam suatu jaringan (Sulistiawati, Lubis, \& Mulyani, 2014). Wasserman dan Faust (1994), analisis SNA menitikberatkan pada interaksi antar-aktor dalam suatu jaringan. Dalam menganalisis SNA diperlukan network atau grafik yang terdiri atas node (titik) yang merepresentasikan aktor dalam suatu jaringan sosial dan edge atau garis yang menggambarkan interaksi antar-aktor. Hubungan antar-node dalam SNA terbagi menjadi dua, yaitu directional relations dan non- 
directional relations. Directional relations berlaku ketika hubungan yang terjadi antaraktor merupakan pilihan daring masing-masing aktor dan tidak berlaku saling berkebalikan. Non-directional relations terjadi ketika hubungan antaraktor bersifat simetris (Wasserman \& Faust, 1994).

Analisis co-authorship network dikategorikan sebagai hubungan non-directional relations, karena hubungan antar-penulis dalam tulisan yang sama bersifat simetris. Hal ini dapat disimulasikan bahwa jika si X menulis bersama dengan si Y maka sudah dipastikan juga kebalikannya bahwa si Y menulisa bersama dengan si X. Sejumlah indikator yang dapat digunakan dalam menganalisis jaringan komunikasi pada tingkat individu, yaitu derajat sentralitas (degree centrality); tingkat kebersamaan (betweeness); dan tingkat kedekatan (closeness) (Prell, 2012).

\subsubsection{Derajat Sentralitas}

Derajat sentralitas merupakan ukuran dalam konsep sociometri untuk mengidentifikasi keaktifan suatu aktor dalam berkomunikasi dengan aktor lainnya dalam jaringan sosial (Wasserman \& Faust, 1994). Seorang star secara derajat sentralitas dalam jaringan sosial merupakan aktor yang paling aktif dan sering berkomunikasi dengan aktor lainnya dalam suatu jaringan sosial. Secara matematis, derajat sentralitas dapat dirumuskan:

$$
C_{D}\left(n_{i}\right)=d\left(n_{i}\right)=x_{i+}=\sum_{1}^{j} x_{i j}=\sum_{1}^{j} x_{j i}
$$

Dimana $C_{D}\left(n_{i}\right)$ merupakan nilai derajat sentralitas dari seorang aktor dalam jaringan sosial. Semakin besar nilai derajat sentralitas semakin aktif suatu aktor dalam berkomunikasi dengan aktor lainnya dalam jaringan sosial (Freeman, 1979).

\subsubsection{Tingkat Kebersamaan}

Ketika dua aktor atau lebih dalam suatu jaringan sosial berkomunikasi terkadang bergantung pada suatu aktor lain yang berada di antara dua aktor atau lebih yang berkomunikasi. Seorang aktor yang menjadi perantara antara dua aktor atau lebih lainnya dalam suatu jaringan sosial sering dianggap memiliki peran yang lebih besar dalam jaringan sosial. Hal ini dikarenakan aktor perantara ini memiliki kontrol atas alur informasi diantara dua aktor atau lebih lainnya atau dengan kata lain aktor perantara ini memiliki kekuatan untuk mengisolasi atau meningkatkan komunikasi antara aktor lainnya (Salamati \& Soheili, 2016). Tingkat kebersamaan seorang aktor dapat dirumuskan sebagai banyaknya kehadiran seorang aktor sebagai perantara komunikasi dibandingkan dengan banyaknya jumlah geodesic pasangan aktor tersebut dalam jaringan sosial. Secara matematis, tingkat kebersamaan dapat dirumuskan:

$$
\text { Tingkat kebersamaan }=\sum_{u<v} \frac{g_{u, v}(C)}{g_{u, v}}, u, v \notin C
$$


Dimana $g_{u, v}(C)$ adalah banyaknya hubungan geodesic antara aktor $u$ dan $v$ melalui aktor $\mathrm{C}$ dan $g_{u, v}$ adalah banyak hubungan antara aktor $u$ dan $v$ (Carrington, Scott, \& Wasserman, 2005).

\subsubsection{Tingkat Kedekatan}

Ukuran tingkat kedekatan ini mengukur seberapa dekat seorang aktor berkominukasi dengan aktor-aktor lainnya dalam jaringan sosial. Ide awal munculnya ukuran tingkat kedekatan ini didasari bahwa seorang aktor akan menjadi sentral jika dapat berinteraksi dengan aktor lainnya lebih mudah dan cepat. Semakin dekat jarak komunkasi antar-aktor maka informasi yang disampaikan semakin lebih mudah dan cepat tersampaikan (Wasserman \& Faust, 1994). Secara matematis, tingkat kedekatan ini dapat dirumuskan:

$$
\text { Tingkat Kedekatan }=\left[\sum_{j=1}^{g} d\left(n_{i}, n_{j}\right)\right]^{-1}
$$

Dimana g adalah banyaknya aktor atau node dalam jaringan sosial, dan jarak geodesic antara $n_{i} n_{i}$ dan $n_{j} n_{j}$.

\section{METODE}

Penelitian ini menggunakan data publikasi Indonesia yang terindeks di Scopus (www.scopus.com) dengan topik "small and medium entrerprises in Indonesia". Data diambil dari tahun 1992 hingga Juni 2016. Data berisi nama penulis, asal instansi penulis, negara, tipe dokumen, dan sitasi. Setelah mengalami cleansing data diketahui ada sejumlah 172 publikasi/artikel yang tidak memiliki nama penulis. Analisis data dengan SNA dengan tema UKM, dilakukan dengan tahapan: (1) eksplorasi data, untuk melihat deskriptif dari penulis; (2) identifikasi hubungan co-authorship penulis, dengan memberikan nilai 1 jika terjadi kegiatan menulis bersama antar-dua penulis; (3) membuat matriks hubungan antar-dua penulis; (4) membuat gambar jaringan sosial co-authorship dari matriks yang dibuat; serta (5) mengukur nilai sentralitas dari penulis yang terdata di jaringan sosial hubungan co-auhtorship penulis.

\section{HASIL DAN PEMBAHASAN}

\subsection{Eksplorasi Deskriptif Penulis}

Berdasarkan data yang terkumpul, diperoleh sebanyak 172 artikel yang terindeks Scopus dengan tema UKM Indonesia dan sebanyak 218 penulis yang berasal dari berbagai negara. Secara distribusi, penulis Indonesia masih mendominasi dalam tulisan dengan topik UKM Indonesia (55,05\%). Diposisi kedua ditempati oleh negara Australia $(8,7 \%)$ dan Malaysia (5,5\%), dan selebihnya dapat lihat Gambar 1. 


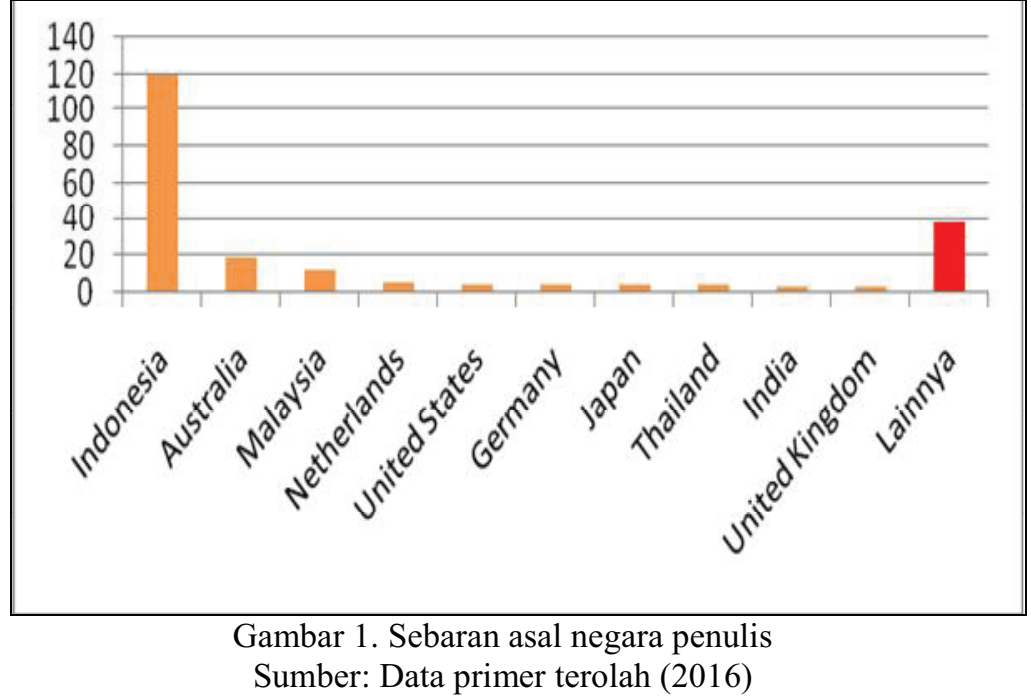

Apabila mengulas lebih dalam asal instansi penulis diketahui bahwa instansi universitas masih mendominasi dalam mengeluarkan tulisan tentang UKM Indonesia. ITB menjadi instansi yang paling produktif dalam mengeluarkan tulisan tentang UKM Indonesia dan terindeks Scopus (Gambar 2). Terlihat bahwa sebagian besar instansi hanya mampu menghasilkan dua tulisan tentang UKM Indonesia. Hal ini dapat menjadi indikasi adanya duplikasi tema tulisan atau kurang perhatian dari instansi di Indonesia terhadap UKM.

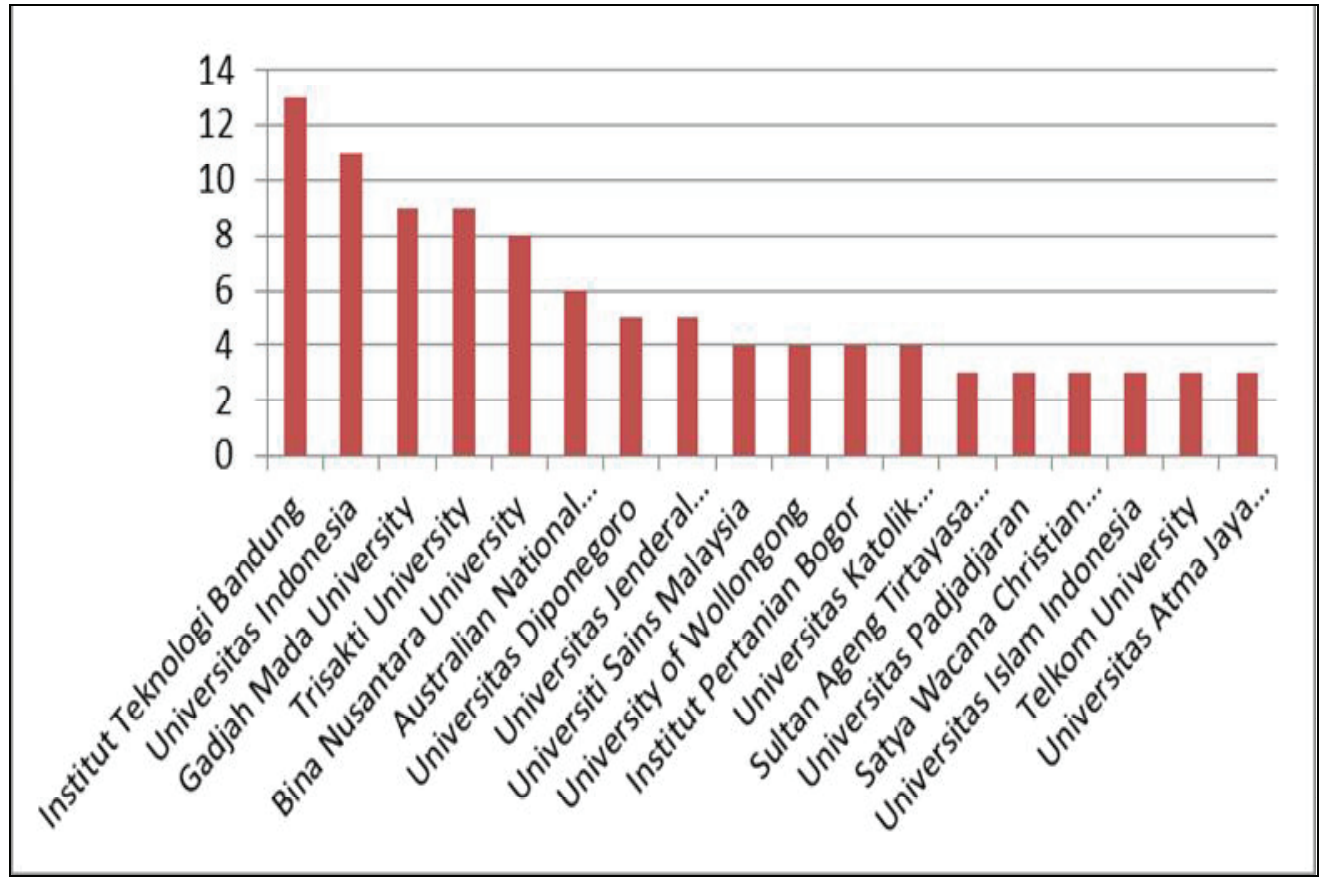

Gambar 2. Distribusi instansi penulis

Sumber: Data primer terolah (2016)

Disisi lain untuk melihat produktivitas penulis yang mengangkat topik UKM Indonesia dapat dilihat pada Gambar 3. Terlihat bahwa Tambunan menjadi penulis yang paling produktif menulis topik UKM Indonesia. Dari Gambar 3 terlihat ada10 besar penulis yang paling produktif, dua dari sepuluh penulis tersebut merupakan warga negara asing 
(Hill dan Berry). Hal ini terjadi oleh dua alasan yang berbeda, Hill produktif menulis tentang UKM Indonesia disebabkan oleh seringnya berkolaborasi dengan penulis Indonesia, sedangkan Berry (warga negara asing asal Canada perlu ber-elaborasi lebih lanjut terkait dengan penulis lain.

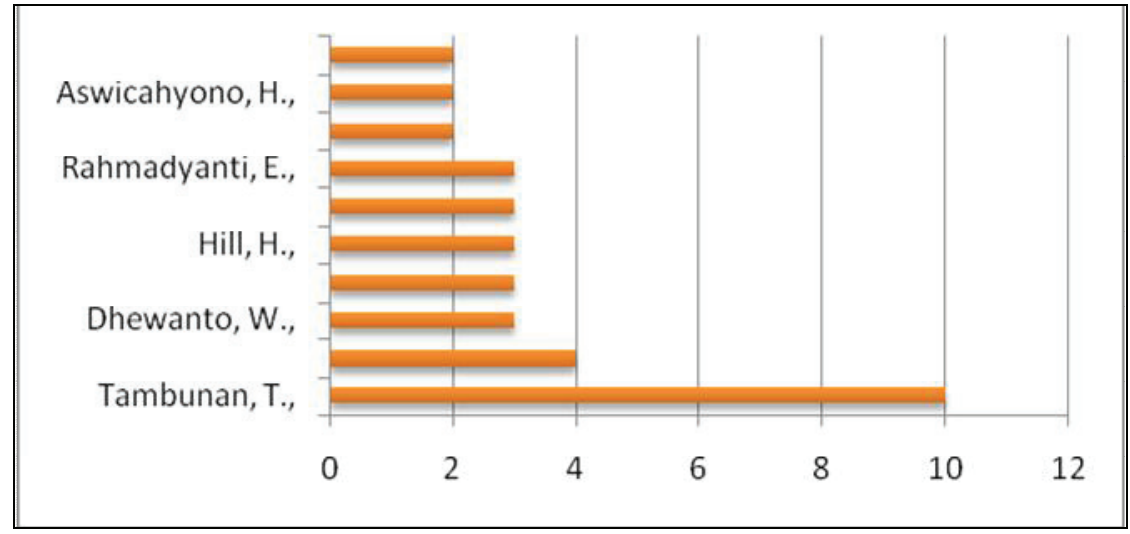

Gambar 3. Produktivitas penulis

Sumber: Data primer terolah (2016)

Terkait co-authorship, perlu dilihat besarnya tingkat kolaborasi penulis. Tabel 1 menunjukkan bahwa secara rata-rata bahwa tingkat kolaborasi penulis sebesar 64,5\%. Hal ini berarti rata-rata sebesar $64,5 \%$ penulis memilih menulis secara bersama-sama (coauthorship).

Tabel 1. Tingkat Kolaborasi Penulis

\begin{tabular}{|c|c|c|c|c|c|c|c|c|c|c|c|c|c|c|c|c|c|c|c|c|c|}
\hline \multirow{3}{*}{$\%$ Kolaboras } & \multicolumn{20}{|c|}{ Tahun } & \multirow{2}{*}{ \% Kolaborasi } \\
\hline & 1992 & 1994 & 1995 & 1999 & 2000 & 2001 & 2002 & 2003 & 2005 & 2006 & 2007 & 2008 & 2009 & 2010 & 2011 & 2012 & 2013 & 2014 & 2015 & 2016 & \\
\hline & $0,00 \%$ & $0,00 \%$ & $100,00 \%$ & $0,00 \%$ & $00,00 \%$ & $66,67 \%$ & $50,00 \%$ & $33,33 \%$ & $33,33 \%$ & $42,86 \%$ & $0,00 \%$ & $16,67 \%$ & $0,00 \%$ & $\mid 57,14 \%$ & $663,64 \%$ & $61,54 \%$ & 7 78,95\% & $\mid 76,67 \%$ & $72,73 \%$ & $671,43 \%$ & $61,45 \%$ \\
\hline
\end{tabular}

Berdasarkan hasil analisis di atas terlihat bahwa penulis yang paling produktif adalah Tambunan dan instansi yang paling banyak menulis tentang UKM Indonesia adalah ITB.

\subsection{SNA Co-Authorship}

Pola jaringan sosial yang terbentuk dari artikel tentang UKM Indoneisa yang terindeks di Scopus dapat dilihat pada Gambar 4. Terlihat dalam pola jaringan sosial terdapat beberapa grup jaringan sosial yang terbentuk. Hal tersebut mengindikasikan bahwa masih banyaknya publikasi yang terpisah-pisah tidak berkolaborasi secara besar. Untuk itu, sangat dimungkinkan dampak dari tulisan yang dipublikasikan berdampak kecil dan berpotensi terjadi duplikasi tema yang sama. Hal ini juga berdampak kurang komprehensifnya tulisan yang dihasilkan. 


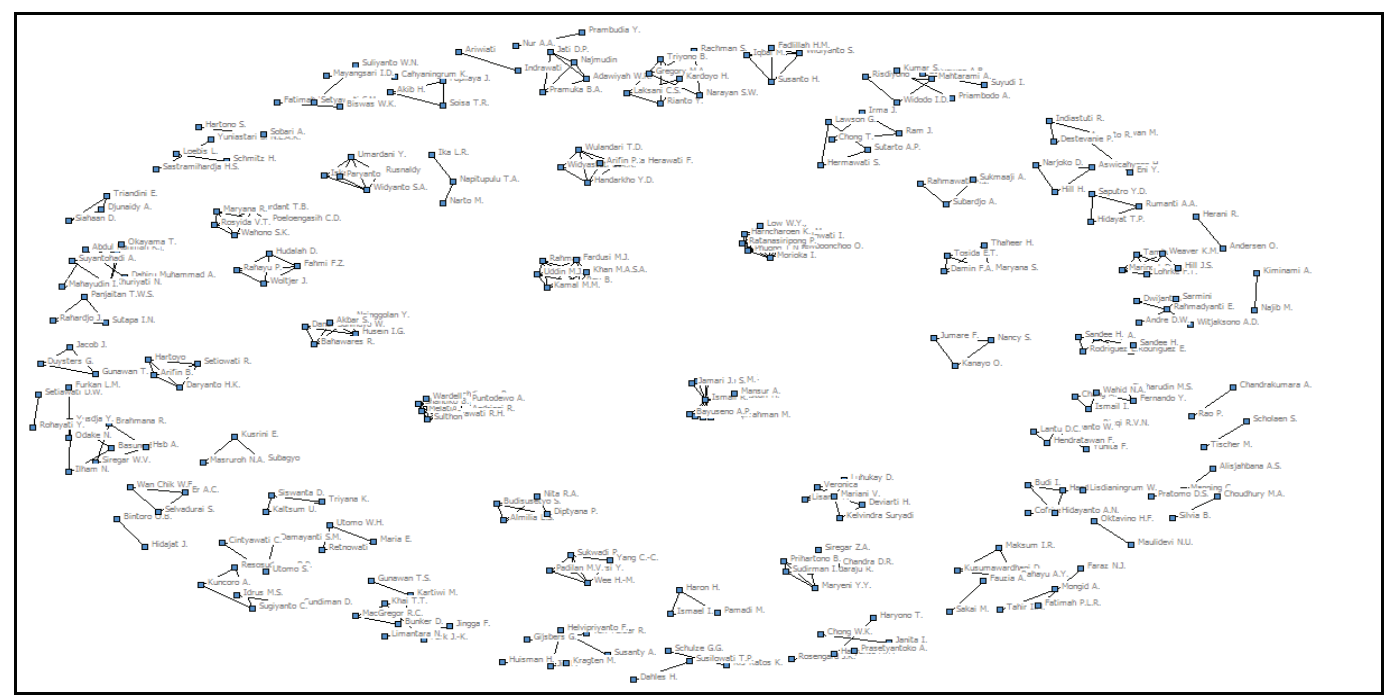

Gambar 4. Jaringan sosial antar-penulis publikasi tentang UKM Indonesia Sumber: Data primer terolah (2016)

Dalam mengukur sentralitas aktor dalam jaringan sosial co-authorship melihat sentralitas dari tiap aktor dalam jariangan sosial (Tabel 2). Pada Tabel 2 hanya ditampilkan 20 besar aktor dengan nilai sentralitas tertinggi. Secara kebetulan terlihat bahwa aktor Ismail $\mathrm{R}$ memiliki peringkat tertinggi di ketiga pengukuran sentralitas. Hal ini bermakna bahwa Ismail $\mathrm{R}$ memiliki tingkat keaktifan (derajat sentralitas) yang tinggi dalam komunikasi co-authorship di antara penulis dalam jaringan sosial. Dari sisi kedekatan dengan aktor lainnya (closeness) Ismail $\mathrm{R}$ merupakan orang yang paling dekat dengan aktor lainnya jika dibandingkan penulis lainnya. Dari sisi seorang mediator informasi (betweeness), Ismail $\mathrm{R}$ juga merupakan seorang perantara co-authorship yang handal.

Hal yang menarik adalah terjadi perbedaan hasil antara analisis aktor dengan metode deskriptif hasil analisis jaringan sosial hubungan co-authorship. Pada analisis sebelumnya diketahui bahwa penulis paling produktif adalah Tambunan. Apabila dilihat lebih jauh mengenai karakteristik publikasi Tambunan, ia lebih banyak menulis secara mandiri (tidak berkolaborasi). Selain aspek produktivitas, perlu melihat hubungan coauthorship antar-penulis pada analisis jaringan sosial. 
Tabel 2. Nilai Sentralitas Tulisan Tentang UKM Indonesia Terindeks Scopus

\begin{tabular}{|c|c|c|c|c|c|c|}
\hline Authors & Degree & $\begin{array}{c}\text { Rank } \\
\text { Degree }\end{array}$ & Closeness & $\begin{array}{c}\text { Rank } \\
\text { Closeness }\end{array}$ & Betweenness & $\begin{array}{c}\text { Rank } \\
\text { betwenness }\end{array}$ \\
\hline Ismail R. & 11 & 1 & 100787 & 1 & 38 & 1 \\
\hline Purnomo H. & 8 & 2 & 101753 & 13 & 2,667 & 10 \\
\hline Achdiawan R. & 8 & 2 & 101753 & 13 & 2,667 & 10 \\
\hline Irawati R.H. & 8 & 2 & 101753 & 13 & 2,667 & 10 \\
\hline Kaewboonchoo O. & 7 & 5 & 102075 & 22 & 0 & 18 \\
\hline Isahak M. & 7 & 5 & 102075 & 22 & 0 & 18 \\
\hline Susilowati I. & 7 & 5 & 102075 & 22 & 0 & 18 \\
\hline Phuong T.N. & 7 & 5 & 102075 & 22 & 0 & 18 \\
\hline Morioka I. & 7 & 5 & 102075 & 22 & 0 & 18 \\
\hline Harncharoen K. & 7 & 5 & 102075 & 22 & 0 & 18 \\
\hline Low W.Y., & 7 & 5 & 102075 & 22 & 0 & 18 \\
\hline Ratanasiripong P. & 7 & 5 & 102075 & 22 & 0 & 18 \\
\hline MelatiA. & 6 & 13 & 101755 & 16 & 0 & 18 \\
\hline Sulthon & 6 & 13 & 101755 & 16 & 0 & 18 \\
\hline Shantiko B. & 6 & 13 & 101755 & 16 & 0 & 18 \\
\hline Wardell & 6 & 13 & 101755 & 16 & 0 & 18 \\
\hline Govindaraju R. & 5 & 17 & 102719 & 30 & 6 & 2 \\
\hline Mariani V. & 5 & 17 & 102719 & 30 & 6 & 2 \\
\hline Rahman M.H. & 5 & 17 & 102719 & 30 & 0 & 18 \\
\hline Fardusi M.J. & 5 & 17 & 102719 & 30 & 0 & 18 \\
\hline
\end{tabular}

Sumber: Data primer terolah (2016)

Selanjutnya akan dilakukan penggabungan metode antara metode deskriptif dengan metode SNA untuk menentukan aktor dalam publikasi tentang UKM Indonesia. Gambar 5 menunjukkan bahwa sangat sedikit orang yang produktif jika dilihat dari analisis jaringan sosial co-authorship. Terlihat jaringan yang terbentuk terpisah-pisah, hal tersebut megindikasikan bahwa orang-orang yang produktif menulis lebih banyak menulis secara sendiri (tidak berkolaborasi). 


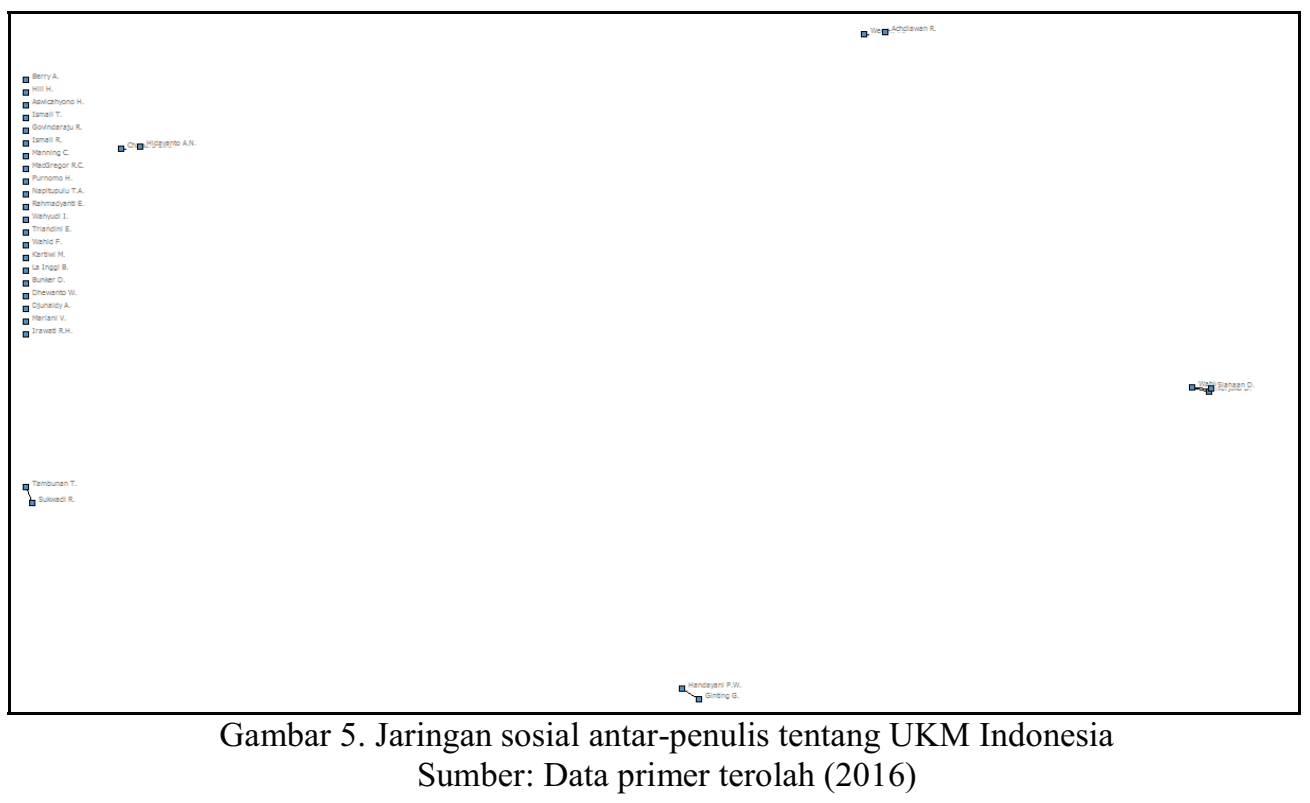

Dalam menganalisis aktor dalam jaringan sosial hubungan co-authorship dilakukan pengukuran tiga ukuran sentralitas untuk penulis yang produktif (lebih dari satu publikasi). Penilaian aktor kembali berubah, Narjoko D, Wahid dan-Siahaan menjadi aktor yang produktif dan aktif dalam jaringan sosial co-authorship. Ada hal yang menarik dalam dalam sentralitas di Tabel 3. Terlihat bahwa tidak adanya nilai betweenes dalam jaringan sosial hubungan co-authorship yang terbentuk, hal ini menjadi indikasi bahwa penulis yang produktif bukan merupakan orang yang mampu mengontrol alur informasi.

Tabel 3.Ukuran Sentralitas PenulisProduktif

\begin{tabular}{|c|c|c|c|c|c|}
\hline Authors & Degree & rank_Deg & Betweeness & Closeness & rank_Clos \\
\hline Narjoko D. & 2 & $\mathbf{1}$ & 0.000 & 962.000 & $\mathbf{1}$ \\
\hline Wahid N.A. & 2 & 1 & 0.000 & 962.000 & 1 \\
\hline Siahaan D. & 2 & 1 & 0.000 & 962.000 & 1 \\
\hline Sukwadi R. & 1 & 4 & 0.000 & 993.000 & 4 \\
\hline Handayani P.W. & 1 & 4 & 0.000 & 993.000 & 4 \\
\hline Ginting G. & 1 & 4 & 0.000 & 993.000 & 4 \\
\hline Wee H.-M. & 1 & 4 & 0.000 & 993.000 & 4 \\
\hline Chandra D.R. & 1 & 4 & 0.000 & 993.000 & 4 \\
\hline Hidayanto A.N. & 1 & 4 & 0.000 & 993.000 & 4 \\
\hline Achdiawan R. & 1 & 4 & 0.000 & 993.000 & 4 \\
\hline Berry A. & 0 & 11 & 0.000 & 1.024 .000 & 11 \\
\hline Hill H. & 0 & 11 & 0.000 & 1.024 .000 & 11 \\
\hline Aswicahyono H. & 0 & 11 & 0.000 & 1.024 .000 & 11 \\
\hline Ismail T. & 0 & 11 & 0.000 & 1.024 .000 & 11 \\
\hline Govindaraju R. & 0 & 11 & 0.000 & 1.024 .000 & 11 \\
\hline Ismail R. & 0 & 11 & 0.000 & 1.024 .000 & 11 \\
\hline Manning C. & 0 & 11 & 0.000 & 1.024 .000 & 11 \\
\hline
\end{tabular}




\begin{tabular}{|c|c|c|c|c|c|}
\hline MacGregor R.C. & 0 & 11 & 0.000 & 1.024 .000 & 11 \\
\hline Purnomo H. & 0 & 11 & 0.000 & 1.024 .000 & 11 \\
\hline Napitupulu T.A. & 0 & 11 & 0.000 & 1.024 .000 & 11 \\
\hline
\end{tabular}

Setelah diketahui penulis-penulis yang merupakan aktor "star", selanjutnya dilakukan analisis terhadap instansi aktor asal penulis dalam jaringan sosial hubungan coauthorship terkait artikel UKM Indonesia. Gambar 6 menunjukkan pola jaringan sosial instansi asal penulis. Dari gambar tersebut terlihat ada satu kelompok jaringan yang cukup kompleks (tingkat co-authorship tinggi), yaitu dalam kelompok jaringan sosial hubungan co-authorship tersebut instansi dari Universitas Indonesia merupakan aktor sentral dalam jaringan sosial.

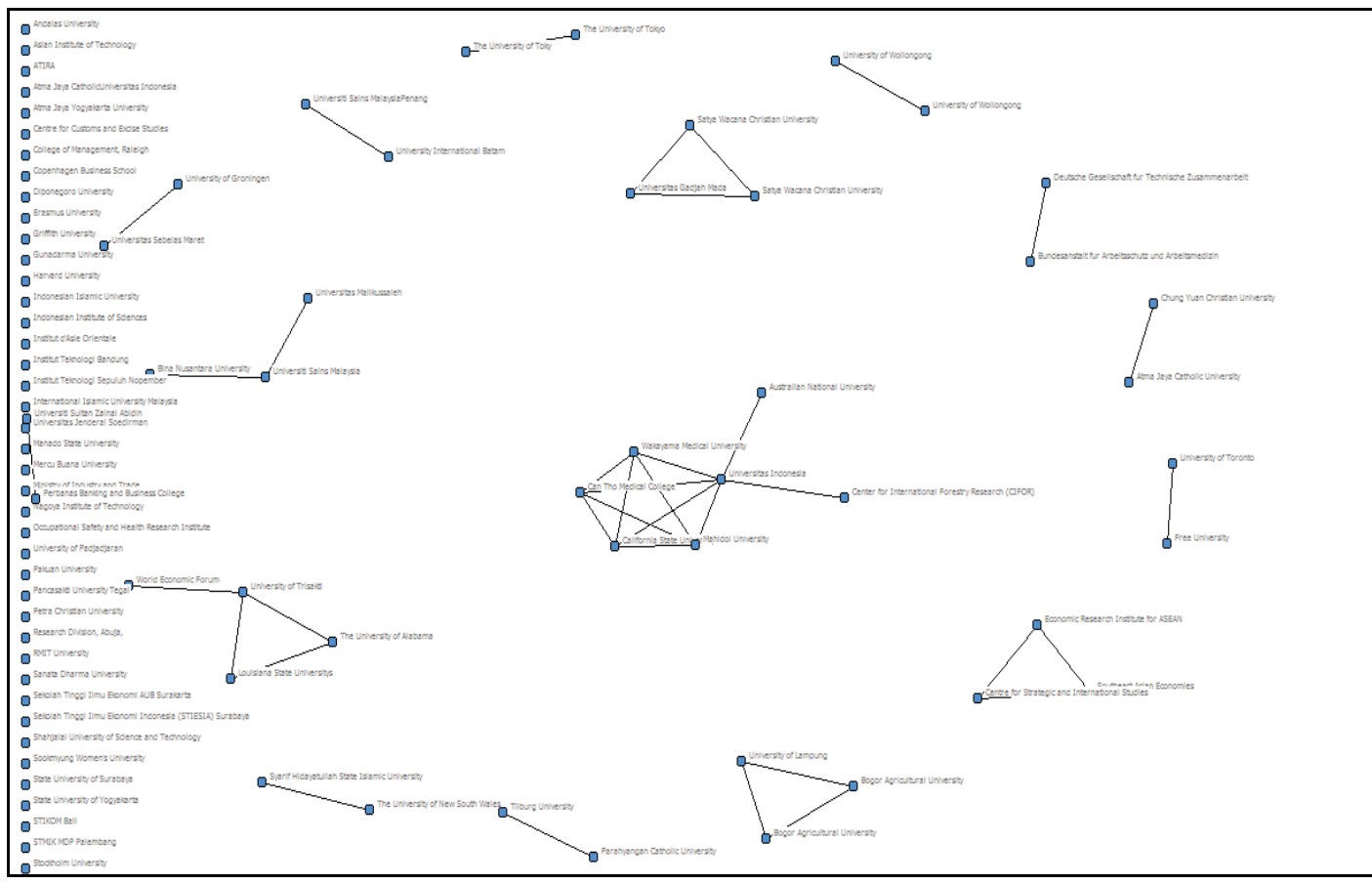

Gambar 6. Jaringan sosial instansi asal penulis pada publikasi tentang UKM Indonesia Sumber: Data primer terolah (2016)

Nilai-nilai sentralitas dari jaringan sosial hubungan co-authorship dari aktor instansi dapat dilihat pada Tabel 4. Tabel 4 menunjukkan bahwa Universitas Inodensia memiliki peringkat tertinggi baik dari keaktifan dalam jaringan sosial (degree),kedekatan dengan instansi lainnya (closeness) maupun dari sisi aktor yang mampu dari sisi pengontrol arus informasi (betweeness). Tampak bahwa baik secara visual grafik maupun secara pengukuran sentralitas, Universitas Indonesia merupakan aktor "star" dalam jaringan sosial instansi penulis hubungan co-authorship. Selain itu, dalam tabel 3 terlihat bahwa aktor "star" diurutan kedua dari aspek keaktifan dan kedekatan dengan instansi lainnya berasal dari instansi luar negeri (Can Tho Medical College, Wakayama Medical University dan California State University). Hal ini dapat menjadi perhatian pemangku kebijakan sebaiknya mengaktifkan instansi dalam negeri agar lebih memperhatikan pengembangan UKM Indonesia. 
Apabila dibandingkan dengan hasil penelusuran aktor instansi yang berperan dalam pengembangan UKM Indonesia melalui publikasi internasional dengan metode deskriptif sebelumnya, diperoleh hasil yang berbeda dengan hasil dengan metode SNA. Pada metode deskriptif didapat instansi Institut Teknologi Bandung di anggap sebagai aktor "star" dalam publikasi internasonal tentang UKM indonesia jika dilihat dari aspek produktivitas. Lainnya halnya dengan metode SNA, diperoleh Universitas Indonesia sebagai aktor "star" dalam jaringan sosial hubungan co-authorship publikasi tentang UKM Indonesia.

Tabel 4.Ukuran Sentralitas Asal Instansi Penulis

\begin{tabular}{|l|c|c|c|c|c|c|}
\hline \multicolumn{1}{|c|}{ Nama Institusi } & Degree & rank_Deg & Betweenness & rank_Bet & Closeness & rank_Clos \\
\hline Universitas Indonesia & 6 & 1 & 9 & 1 & 12766 & 1 \\
\hline Can Tho Medical College & 4 & 2 & 0 & 4 & 12768 & 2 \\
\hline $\begin{array}{l}\text { Wakayama Medical } \\
\text { University }\end{array}$ & 4 & 2 & 0 & 4 & 12768 & 2 \\
\hline California State University & 4 & 2 & 0 & 4 & 12768 & 2 \\
\hline Mahidol University & 4 & 2 & 0 & 4 & 12768 & 2 \\
\hline University of Trisakti & 3 & 6 & 2 & 2 & 13111 & 8 \\
\hline Universiti Sains Malaysia & 2 & 7 & 1 & 3 & 13226 & 12 \\
\hline Louisiana State Universitys & 2 & 7 & 0 & 4 & 13112 & 9 \\
\hline The University of Alabama & 2 & 7 & 0 & 4 & 13112 & 9 \\
\hline Bogor Agricultural University & 2 & 7 & 0 & 4 & 13226 & 12 \\
\hline $\begin{array}{l}\text { Economic Research Institute } \\
\text { for ASEAN }\end{array}$ & 2 & 7 & 0 & 4 & 13226 & 12 \\
\hline $\begin{array}{l}\text { Satya Wacana Christian } \\
\text { University }\end{array}$ & 2 & 7 & 0 & 4 & 13226 & 12 \\
\hline Southeast Asian Economies & 2 & 7 & 0 & 4 & 13226 & 12 \\
\hline Bogor Agricultural University & 2 & 7 & 0 & 4 & 13226 & 12 \\
\hline $\begin{array}{l}\text { Centre for Strategic and } \\
\text { International Studies }\end{array}$ & 2 & 7 & 0 & 4 & 13226 & 12 \\
\hline $\begin{array}{l}\text { Satya Wacana Christian } \\
\text { University }\end{array}$ & 2 & 7 & 0 & 4 & 13226 & 12 \\
\hline Universitas Gadjah Mada & 2 & 7 & 0 & 4 & 13226 & 12 \\
\hline University of Lampung & 2 & 7 & 0 & 4 & 13226 & 12 \\
\hline $\begin{array}{l}\text { Australian National } \\
\text { University }\end{array}$ & 1 & 19 & 0 & 4 & 12771 & 6 \\
\hline $\begin{array}{l}\text { Center for International } \\
\text { Forestry Research (CIFOR) }\end{array}$ & 1 & 19 & 0 & 4 & 12771 & 6 \\
\hline World Economic Forum & 1 & 19 & 0 & 4 & 13113 & 11 \\
\hline
\end{tabular}

Sumber: Data primer terolah (2016)

\section{KESIMPULAN}

Penulis yang berkontribusi terhadap perkembangan UKM di Indonesia didominasi dari kalangan universitas besar, yaitu ITB, UI, UGM, Triskati, dan BINUS. Hasil analisis jaringan sosial menunjukkan bahwa Narjoko merupakan penulis yang produktif dan menjadi 
aktor sentral dalam jaringan tentang UKM Indonesia. UI merupakan instansi yang aktif mempublikasikan dan aktor yang aktif dalam jaringan sosial instansi yang menulis tentang UKM Indonesia. Hasil ini dapat menjadi rekomendasi bagi pengambil kebijakan untuk memberikan insentif dan reward bagi penulis dan instansi tersebut. Selain itu, juga dapat menjadi pemicu meningkatnya produktivitas penulis dalam memberikan kontribusi di bidang UKM di Indonesia. Secara umum, pola jaringan sosial hubungan co-authorship antar-penulis masih terlihat terpisah-pisah, menunjukkan masih terkotak-kotaknya jaringan penulis dalam mengkaji/meneliti UKM Indonesia. Analisis jaringan sosial ini dapat mendeteksi tingkat sentralitas seorang aktor individu/institusi. Tingkat produktivitas publikasi ilmiah yang dikeluarkan dan aspek jaringan sosial dapat dipertimbangkan sebagai alat ukur untuk menentukan kontribusi penulis atau institusi dalam bidang kajian tertentu.

\section{DAFTAR PUSTAKA}

Aharoni, Y. 1994. How Small Firms Can Achieve Competitive Advantages in an Interdependent World. New York: Oxford University Press.

Carrington, P. J., Scott, J., \& Wasserman, S. 2005. Models and Methods in Social Network Analysis. (P. J. Carrington, J. Scott, \& S. Wasserman, Eds.). New York: Cambridge University Press.

Freeman, L. C. 1979. Centrality in Social Networks Conceptual Clarification, 1(1968), 215-239.

Glänzel, W., \& Schubert, A. 2005. Analyzing Scientific Networks Through co-Authorship. Handbook of Quantitative Science and Technology Research, (1963), 257-276. https://doi.org/10.1007/1-4020-2755-9.

Koperasi dan UKM, K. 2015. Renstra Kementerian Koperasi dan UKM 2015-2019. (www.depkop.go.id).

Liu, X., Bollen, J., Nelson, M. L., \& Van De Sompel, H. 2005. Co-authorship Networks in the Digital Library Research Community. Information Processing and Management, 41(6), 1462-1480. https://doi.org/10.1016/j.ipm.2005.03.012.

Nadhiroh, I. M., Aidi, M. N., \& Sartono, B. 2015. Publikasi Internasional Indonesia Bidang Kimia Scientometrics Studies: Social Network Analysis of Indonesian International Publication on Chemistry. Warta KIML, 13, 75-90.

Prell, C. 2012. Social Network Analysis: History, Theory, and Methodology. Siangapore: SAGE.

Salamati, P., \& Soheili, F. 2016. Social Network Analysis of Iranian Researchers in the Field of Violence. Chinese Journal of Traumatology, 19 (5), 4-10. https://doi.org/10.1016/j.cjtee.2016.06.008.

Schwab, K., Sala-i-Martin, X., \& Brende, B. 2015. The Global Competitiveness Report 2015-2016. World Economic Forum (Vol. 5). https://doi.org/92-95044-35-5

Sulistiawati, A., Lubis, D. P., \& Mulyani, S. 2014. Analisis Jaringan Sosial dalam Gabungan, 2(2), 76-82. 